Chronic Obstructive Pulmonary Diseases: Journal of the COPD Foundation

\author{
Original Research
}

\title{
High Intensity Non-Invasive Positive Pressure Ventilation (HINPPV) for Stable Hypercapnic Chronic Obstructive Pulmonary Disease (COPD) Patients
}

Mark Weir, MBChB ${ }^{1}$ Nathaniel Marchetti, DO ${ }^{1}$ Aaron Czysz, MD $^{1}$ Nicholas Hill, MD $^{2}$ Frank Sciurba, MD $^{3}$ Patrick Strollo, $\mathrm{MD}^{3}$ Gerard J. Criner, $\mathrm{MD}^{1}$

\section{Abstract}

Introduction: High intensity non-invasive positive pressure ventilation (HI-NPPV) is an algorithm of non-invasive ventilation that has been shown to improve partial pressure of carbon dioxide $\left(\mathrm{PaCO}_{2}\right)$, health-related quality of life and mortality in hypercapnic chronic obstructive pulmonary disease (COPD) patients.

Objective: Assess 3 months of HI-NPPV in stable hypercapnic COPD patients.

Methods: A single arm, non-randomized pilot study of HI-NPPV. Patients were eligible if they had clinically stable COPD and daytime arterial $\mathrm{PaCO}_{2}>50 \mathrm{mmHg}$.

Results: Nine patients completed therapy. Patient characteristics: 2 male: 7 female, mean age of 64.4 years (SD \pm 6.6 ), mean forced expiratory volume in 1 second ( $\left.F E V_{1}\right)$ of $26 \%$ ( $S D \pm 6.73$ ), 8 patients on long term oxygen therapy (LTOT) and a median body mass index (BMI) of 26.6 (interquartile range [IQR] 25.5 - 32.5).

Outcomes: There was a mean reduction in daytime $\mathrm{PaCO}_{2}$ by $4.66 \mathrm{mmHg}(p=0.01)$ and bicarbonate by 2.16 $\mathrm{mmHg}(p=0.005)$. There was no statistically significant difference in lung function, maximal inspiratory pressures or 6 minute walk distance. There was no statistically significant difference in sleep duration, efficiency or percentage of sleep stage 3 (N3) or rapid eye movement (REM). The Chronic Respiratory Questionnaire (CRQ) showed a trend towards improvement with an increase of 2.69 points ( $p=0.054)$, the dyspnea domain showed a statistically significant improvement $(p=0.03)$. The Calgary Sleep Apnea Quality of Life Index (SAQLI) detected an improvement in daily functioning $(p=0.007)$. The Severe Respiratory Insufficiency (SRI) Questionnaire showed a trend to improvement overall $(p=0.05)$. Four patients had COPD exacerbations during the follow up period.

Conclusions: HI-NPPV is able to substantially reduce $\mathrm{PaCO}_{2}$ in hypercapnic COPD patients; we detected a positive effect on quality of life measures with no significant change in sleep quality.

\footnotetext{
Abbreviations: high intensity non-invasive positive pressure ventilation, $\mathrm{HI}-\mathrm{NPPV}$; partial pressure of carbon dioxide, $\mathrm{PaCO}_{2}$; $\mathrm{chronic}$ obstructive pulmonary disease, COPD; forced expiratory volume in 1 second, FEV $\mathbf{1}$; long term oxygen therapy, LTOT; body mass index, BMI; interquartile range, IQR; sleep stage 3, N3; rapid eye movement, REM; Chronic Respiratory Questionaire, SRQ; Calgary Sleep Apnea Quality of Life Index, SAQOL; Severe Respiratory Insufficiency, SRI; non-invasive positive pressure ventilation, NPPV; carbon dioxide, $\mathbf{C O}_{2}$; inspiratory positive airway pressure, IPAP; forced vital capacity, FVC; total lung capacity, TLC; apnea hypopnea index, AHI; arterial blood gas, ABG; maximal inspiratory pressure, PI max; polysomnography, PSG; Global initiative for chronic Obstructive Lung Disease, GOLD; expiratory positive airway pressure, EPAP; inspiratory to expiratory time ratio, I:E; residual volume, RV; bilevel positive airway pressure, BiPAP

Funding Support: The study was funded by Philips Respironics, USA.

Date of Acceptance: August 4, 2015

Citation: Weir M, Marchetti N, Czysz A, et al. High intensity non-invasive positive pressure ventilation for stable hypercapnic chronic obstructive pulmonary disease patients. Chronic Obstr Pulm Dis (Miami). 2015; 2(4): 313-320. doi: http://dx.doi.org/10.15326/ jcopdf.2.4.2015.0145
} 
1 Division of Pulmonary and Critical Care Medicine, Temple University School of Medicine, Philadelphia, Pennsylvania

2 Division of Pulmonary and Critical Care Medicine, Tufts Medical Center, Boston, Massachusetts

3 University of Pittsburgh Medical Center, Division of Pulmonary, Allergy and Critical Care Medicine, Montefiore Hospital, Pittsburgh, Pennsylvania

\section{Address correspondence to:}

Mark Weir, MBChB

Division of Pulmonary and Critical Care Medicine

Temple University School of Medicine

745 Parkinson Pavilion

3401 North Broad Street

Philadelphia Pa, 19140

Phone: 215-707-5864

Fax: 215-707-6867

Email: mark.weir@tuhs.temple.edu

\section{Keywords:}

chronic obstructive pulmonary disease; COPD; high intensity noninvasive pressure ventilation; HINPPV; non invasive ventilation; bilevel positive airway pressure; BIPAP

\section{Introduction}

Once patients with chronic obstructive pulmonary disease (COPD) develop hypercapnic respiratory failure they are at increased risk for exacerbations, rehospitalization and mortality. ${ }^{1-4}$ Evidence to support interventions for the treatment of chronic respiratory failure in COPD, except for the use of long-term oxygen therapy (LTOT), has been lacking. ${ }^{5}$ Non-invasive positive pressure ventilation (NPPV) is commonly instituted in COPD patients with hypercapnia during hospitalization for acute exacerbations and subsequently continued as an outpatient in a sporadic fashion. However, the evidence to support this intervention is poor with no consistent benefit in survival, need for re-hospitalization, dyspnea, quality of life, respiratory muscle strength, sleep efficiency or 6 minute walk distance. ${ }^{6}$ Several factors predispose severe COPD patients to chronic respiratory failure; severe airflow obstruction, hyperinflation, imbalances in the respiratory muscle length-tension relationship, malnutrition, chronic systemic steroid use and comorbid conditions. ${ }^{7}$ Some investigators have suggested that chronic nocturnal NPPV could provide respiratory muscle rest thus enhancing recovery from chronic respiratory muscle fatigue and thereby improving respiratory muscle strength, improving lung function and gas exchange. ${ }^{8}$ NPPV used nocturnally improves nighttime ventilation and can reduce $\mathrm{PaCO}_{2}$ both at night and during the day. ${ }^{9}$ An improvement in nocturnal hypoventilation is thought to reset the respiratory center sensitivity for carbon dioxide $\left(\mathrm{CO}_{2}\right){ }^{10}$ It has been theorized that NPPV can improve ventilation/perfusion relationships through recruitment of poorly ventilated lung units although this has not been successfully demonstrated. Prior reports of chronic nocturnal NPPV's ability to improve outcomes in COPD patients with chronic respiratory failure have been inconsistent. This has been attributed to problems in prior study design small numbers of participants, short duration of NPPV, a failure to select individuals with sufficient hypercapnia and inappropriate levels of NPPV that resulted in poor patient tolerance, limited adherence and insufficient levels of ventilation to improve gas exchange or provide respiratory muscle rest. ${ }^{11,12}$

Recently published studies have shown positive results with high-intensity non-invasive positive pressure ventilation (HI-NPPV), ${ }^{13-15}$ a different algorithm of NPPV utilizing higher inspiratory positive airway pressure (IPAP) and back up respiratory rates to provide greater ventilator support with an aim to provide more robust ventilation and respiratory muscle resting indicated by normalization of $\mathrm{PaCO}_{2}$. There is a growing body of evidence that HI-NPPV can improve blood gas, ${ }^{16}$ lung function, ${ }^{15}$ health-related quality of life ${ }^{17}$ and now survival. ${ }^{18}$ However, other groups have not been able to replicate these results. ${ }^{9}$ Concerns remain that the high inspiratory pressures of $\mathrm{HI}$ NPPV will not be tolerated and could possibly induce worsening hyperinflation in severe COPD patients.

The purpose of this pilot study was to attempt to replicate the positive outcomes of HI-NPPV in stable hypercapnic COPD patients through assessment of daytime $\mathrm{PaCO}_{2}$ levels, tolerance, effect on quality of life measures and polysomnography.

\section{Methods}

\section{Study Design}

This was a multicenter non-randomized pilot study of stable hypercapnic COPD patients. Due to issues with patient recruitment at some clinical centers, all patients in this report came from Temple University Hospital. The HI-NPPV initiation and outpatient treatment protocol is based on prior work of Windisch et al. ${ }^{15}$ 


\section{Patient Selection}

Patients were recruited from Temple University outpatient pulmonary clinic if they had a prior diagnosis of COPD, age $<80$ years, $\mathrm{FEV}_{1}<50 \%$ predicted, $\mathrm{FEV}_{1} /$ forced vital capacity (FVC) $<70 \%$, total lung capacity (TLC) $>90 \%$ predicted, BMI $<35 \mathrm{~kg} / \mathrm{m}^{2}$ with a daytime $\mathrm{PaCO}_{2}>50 \mathrm{mmHg}$ and symptoms of hypercapnia. Patients with acute hypercapnic respiratory failure were excluded but patients $>14$ days post hospital discharge were eligible. The patients were recruited over a 24-month period during 2011 and 2012.

ExclusioncriteriaincludedFEV $\mathrm{V}_{1}<15 \%$ predicted,aprior diagnosis of obstructive sleep apnea (apnea hypopnea index $[\mathrm{AHI}]>15$ per hour), history of pneumothorax, diffuse lung disease other than emphysema, current users of NPPV, chronic corticosteroid use, LTOT>5L's/ min or a significant other medical comorbidity that would interfere with the study requirements.

The study received prior approval from Temple University Hospital institutional review board. After informed consent the participants underwent an initial screening including a medical history, physical exam, spirometry and daytime arterial blood gases $(\mathrm{ABG}) / \mathrm{SpO}_{2}$. Participants that met all initial screening criteria underwent further tests including the Epworth Sleepiness Scale, baseline Quality of Life Questionnaires, pulmonary function tests (body plethysmography and diffusion capacity for lung carbon dioxide [DLCO]), maximal inspiratory pressure (PI, max) and a polysomnography study (PSG).

\section{High-Intensity Non Invasive Positive Pressure Ventilation Initiation}

All patients received conventional medical therapy for COPD and LTOT as per Global initiative for chronic Obstructive Lung Disease (GOLD) guidelines. ${ }^{19}$ All patients were hospitalized to initiate HI-NPPV. On the day of admission, a resting arterial blood gas on room air was analyzed, if arterial $\mathrm{PaCO}_{2}$ was $>50 \mathrm{mmHg}$ the patient was eligible for the study. The Respironics BiPAP Synchrony ${ }^{\circledR}$ (Philips-Respironics, USA) device used in the Spontaneous/Timed mode (pressurelimited, time-cycled). The IPAP setting was $16 \mathrm{~cm}$ $\mathrm{H}_{2} \mathrm{O}$ with an expiratory positive airway pressure (EPAP) of $4 \mathrm{~cm} \mathrm{H}_{2} \mathrm{O}$. The IPAP was then titrated to a minimum of $20 \mathrm{~cm} \mathrm{H}_{2} \mathrm{O}$ with a goal to increase the IPAP sequentially to the maximum inspiratory pressure tolerated up to $30 \mathrm{~cm} \mathrm{H}_{2} \mathrm{O}$. In an attempt to establish controlled ventilation, the respiratory rate was gradually increased beyond the spontaneous rate with a targeted back up set respiratory rate of 18-22 breaths/ minute. The inspiratory to expiratory time (I:E) ratio was set to individual patient tolerance but no less than 1:2. Arterial blood gas sampling was performed once daily after at least 4 hours of HI-NPPV to determine if hypercapnia was still present, if so the IPAP was further titrated with a goal of achieving optimal alveolar ventilation and normocapnia while maintaining patient comfort. Patients were discharged once normocapnia was achieved or the $\mathrm{PaCO}_{2}$ did not show further improvement after 3 days of HI-NPPV titration. Upon discharge the patients' goal for adherence was to use the device for at least 6 hours in total during daytime naps and nocturnally. Adherence was assessed with daily phone calls for the first 4 days, then weekly for the first month. Adherence was defined as minimum of 4 hours use per night on 5 out of 7 nights per week. The patients underwent monthly visits to the research center after the first month to ascertain that they were using the device properly. The study staff reviewed the mask and ventilator settings for comfort and recorded any necessary adjustments.

\section{Outcomes}

The primary outcome of the study was the change in $\mathrm{PaCO}_{2}$ at 3 months compared to baseline levels. Secondary outcomes included patient tolerance and changes in lung function, maximal inspiratory pressures, 6-minute walk distance, health-related quality of life, sleep efficiency and quality by polysomnography without ventilator assistance at 3 months compared to baseline measures. All adverse events such as exacerbation, pneumothorax or aspiration pneumonia were recorded.

\section{Statistical Analysis}

Statistical analysis was performed using JMP PRo 10 and SAS. The data is presented as mean \pm standard deviation for normally distributed variables and nonnormally distributed data is presented as median and interquartile range (IQR). For the analysis of differences between pre and post treatment a student's t-test was used and was checked with the Wilcoxon signed rank test. A $p<0.05$ was considered statistically significant. 


\section{Results}

Twenty patients were screened from Temple University Hospital, 9 did not meet inclusion criteria (Figure 1) and 2 dropped out of the study. The remainder of the results will concentrate on the 9 COPD individuals who completed the study.

\section{Figure 1. Study Profile}

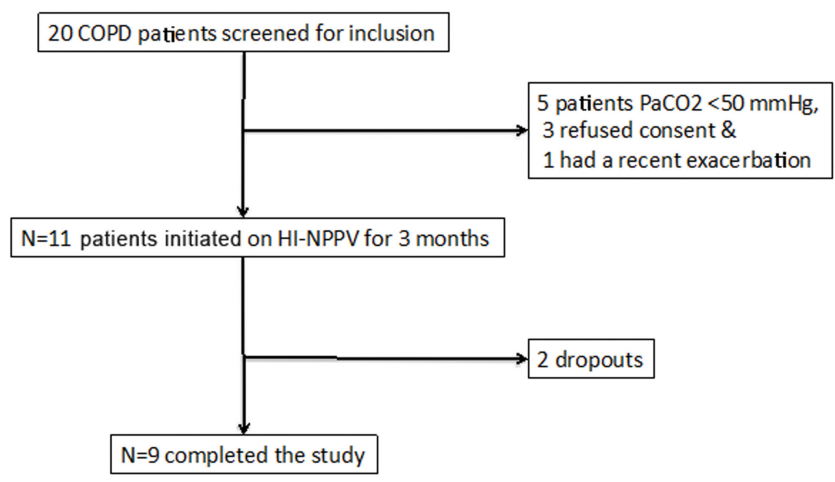

\section{Demographics}

The study included 2 males and 7 females. Mean age was 64.4 yrs. (SD \pm 6.6$)$ all with moderate to severe COPD, mean FEV $126 \%$ of predicted (SD \pm 6.73 ), median smoking was 55 pack years (IQR 45 - 90), 8 out of 9 used LTOT and the median BMI was $26.6 \mathrm{~kg} / \mathrm{m}^{2}$ (IQR $25.5-32.5)$.

\section{Outcomes}

Daytime $\mathrm{PaCO}_{2}$ measured after 3 months of daily nocturnal HI-NPPV compared with baseline measurement showed a mean reduction of $4.66 \mathrm{mmHg}$ $( \pm 4.5 \mathrm{SD})(p=0.01)$. A graphical representation of individual variability in change in $\mathrm{PaCO}_{2}$ is displayed in Figure 2. There was also a significant reduction in arterial blood gas bicarbonate level, mean reduction $2.16 \mathrm{mmHg}(p=0.005)$. There were no statistically significant differences in lung function; maximal inspiratory pressures or 6 minute walk distance (Table 1). There was no statistically significant change in residual volume \% or $\mathrm{FEV}_{1} \%$ surrogate markers of compliance.

\section{Sleep and Quality of Life}

A baseline sleep study in the whole group ( $n=9)$ did not indicate the presence of significant sleep apnea, AHI median 2.4 (IQR 1.25 - 3.95). Not all patients completed the repeat polysomnography after treatment.

\section{Figure 2. Graph Showing Participant Variability of Change in $\mathrm{PaCO}_{2}$ Over 3 Months of HI-NPPV}

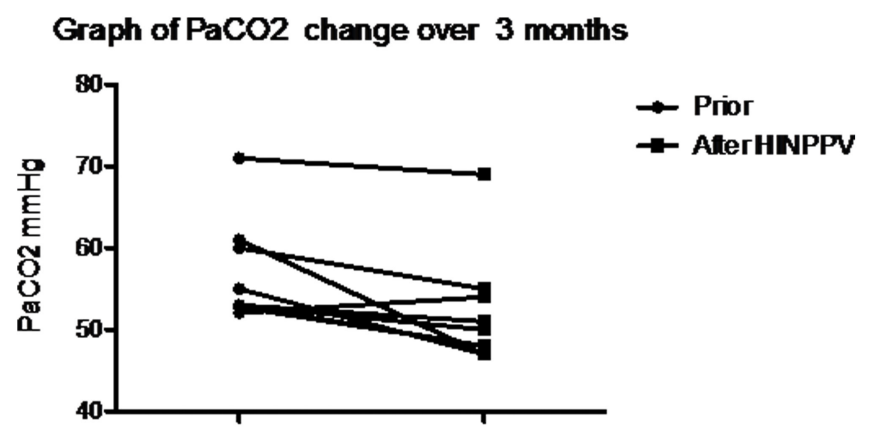

Pre and post HIPPV

In those that did $(n=5)$ there was no statistically significant difference in terms of sleep duration, efficiency or quality as determined by percentage of N3 or REM (Table 2). The Chronic Respiratory Questionnaire (CRQ) ${ }^{20}$ showed a trend to improvement overall with an increase of $2.69(p=0.054)$, the dyspnea domain showed a statistically significant improvement ( $p=0.03)$. The Calcary SAQLI questionaire ${ }^{21}$ detected an improvement in domain A - daily functioning $(p=0.007)$. The Severe Respiratory Insufficiency (SRI) Questionnaire $^{22}$ showed an improvement overall $(p=0.05)$ (Table 3).

\section{HI-NPPV and Adverse Events}

The ventilator settings were mean IPAP $27.3( \pm 4.7)$ $\mathrm{cm} \mathrm{H}_{2} \mathrm{O}$ and EPAP $4 \mathrm{~cm} \mathrm{H}_{2} \mathrm{O}$ and mean set rate 15.4 $( \pm 2.9) / \mathrm{min}$. Adherence with daily nocturnal HI-NPPV by patient reported use was good in $5 / 9$ patients. ${ }^{6,17,18}$ Four patients had COPD exacerbations during the follow up period. There were no recorded events of pneumothorax, aspiration or pneumonia.

\section{Discussion}

This single center pilot study in stable severe hypercapnic COPD patients shows HI-NPPV has a positive effect on daytime $\mathrm{PaCO}_{2}$, a concomitant effect on $\mathrm{HCO}_{3}$ with improved health-related quality of life similar to previous studies. ${ }^{15,23,24}$ In patients who were adherent there was a consistent $5 \mathrm{mmHg}$ improvement in $\mathrm{PaCO}_{2}$ compared with non-adherent individuals 


\section{Table 1. Blood Gas Data, Lung Function Parameters and 6-Minute Walk Distance Pre and Post 3 Months HI-NPPV}

\section{Variables}

\begin{tabular}{|c|c|c|}
\hline pH & $7.41( \pm 0.02)$ & \\
\hline $\mathrm{PaCO}_{2}(\mathrm{mmHg})$ & 53.0 (IQR 52.9 - 60.5) & $50(\mathrm{IC}$ \\
\hline $\mathrm{PaO}_{2}(\mathrm{mmHg})$ & 56.8 (IQR $52-60)$ & \\
\hline $\mathrm{HCO}_{3}(\mathrm{mmHg})$ & 34.4 (IQR 33.1 - 37.8) & \\
\hline TLC \% predicted & 107 (IQR 103.5 - 124) & 103 \\
\hline FVC \% predicted & $60.6( \pm 13.6)$ & \\
\hline $\mathrm{FEV}_{1} \%$ predicted & $26( \pm 6.73)$ & \\
\hline $\mathrm{RV} \%$ & 190 (IQR 141 - 218.5) & $156(\mathrm{IQ}$ \\
\hline DLCO \% & 35 (IQR 23 - 44.5) & \\
\hline Max Inspiratory Pressure (kPa) & 7.04 (IQR 3.67 - 7.97) & 6.85 \\
\hline 6 min walk distance $(\mathrm{m})$ & $211( \pm 54)$ & \\
\hline \multicolumn{3}{|c|}{ Data are presented as mean \pm standard deviation or median and inter } \\
\hline \multicolumn{3}{|c|}{ 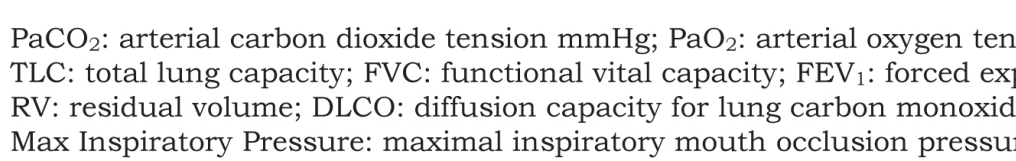 } \\
\hline $\begin{array}{l}\text { Table 2. Sleep P } \\
\text { Data Pre and Po } \\
\text { HI-NPPV }\end{array}$ & st 3 Months & $a p$ \\
\hline
\end{tabular}

\begin{tabular}{l|r|r|r}
\hline Variables & \multicolumn{1}{|c}{ Prior } & $\begin{array}{c}\text { After 3 } \\
\text { months }\end{array}$ & p-value \\
\hline $\mathrm{N}$ & 5 & 5 & \\
\hline Total sleep time & $329( \pm 62.5)$ & $337( \pm 34)$ & 0.73 \\
\hline Sleep efficiency & $80.6( \pm 12.7)$ & $83.6( \pm 6.7)$ & 0.67 \\
\hline $\mathrm{N} 3 \%$ & $16.8( \pm 4.8)$ & $18.3( \pm 7.8)$ & 0.7 \\
\hline $\mathrm{REM} \%$ & $16.2( \pm 7.0)$ & $11.9( \pm 5.6)$ & 0.52 \\
\hline AHI & $2.6( \pm 1.7)$ & $4.6( \pm 5.4)$ & 0.63 \\
\hline Mean $\mathrm{O}_{2}$ sats & $95.8( \pm 1.7)$ & $93.7( \pm 3.5)$ & 0.62 \\
\hline Epworth score & $9.3( \pm 2.6)$ & $7.2( \pm 3.3)$ & 0.38 \\
\hline
\end{tabular}

Data are presented as mean \pm standard deviation or median and interquartile range

N3: stage 3 of sleep; REM: rapid eye movement; AHI: apnea hypoapnea index. in whom there was no significant difference. Through a process of admitting the patients for initiation of HI-NPPV and tailoring the settings to the individual tolerance, we were able to achieve a comparable magnitude of improvement in daytime $\mathrm{PaCO}_{2}$ as reported by Dreher et al. ${ }^{24}$ They report a mean improvement of 6.2 $\mathrm{mmHg}$ in daytime $\mathrm{PaCO}_{2}$ with HI-NPPV compared to our $4.66 \mathrm{mmHg}$. Kohnlein et $\mathrm{al}^{18}$ suggest that it is necessary to reduce $\mathrm{PaCO}_{2}$ by $20 \%$ or to less than $48 \mathrm{mmHg}(6.5 \mathrm{kPa})$ to get maximal benefit. We were unable to achieve these treatment goals despite aggressive pressures with mean IPAP $27.3 \quad( \pm 4.7)$ $\mathrm{cm} \mathrm{H}_{2} \mathrm{O}$ and EPAP $4 \mathrm{~cm}$
$\mathrm{H}_{2} \mathrm{O}$. We attempted to optimize patient ventilator synchrony by maximizing the I:E ratio; we did not increase EPAP as we had screened the group for sleep apnea and wanted to maximize pressure support. One difference between our study and other published studies is the female predominance in the study group. Overall, the small sample size, patient heterogeneity and adherence issues may explain the variable improvement in daytime $\mathrm{PaCO}_{2}$ and quality of life indices. It has been noted in past studies that with cohorts of COPD patients with severe hypercapnia and $\mathrm{PaCO}_{2}>55 \mathrm{mmHg}$ it is easier to demonstrate positive outcomes; our study had a median $\mathrm{PaCO}_{2}$ of $53 \mathrm{mmHg}$ at recruitment. ${ }^{25}$ Kohnlein et al in a single study of $\mathrm{HI}$ NPPV in stable hypercapnic COPD patients $\left(\mathrm{PaCO}_{2}\right.$ $>51 \mathrm{mmHg}$ ) demonstrated a beneficial effect on survival at 1 year using similar inspiratory pressures and back up rates; they stressed the importance of targeting marked reduction in hypercapnia of $20 \%$ or to less than $48 \mathrm{mmHg}$. Other groups have been unable to replicate these results. The inability to replicate may reflect patient selection. Struik et al ${ }^{9}$ in a large multicenter prospective randomized controlled 


\section{Table 3. Quality of Life Measures Pre and Post 3 Months HINPPV}

\begin{tabular}{|c|c|c|c|}
\hline Variables & Prior & $\begin{array}{l}\text { After } 3 \\
\text { months }\end{array}$ & $\begin{array}{c}p- \\
\text { value }\end{array}$ \\
\hline $\begin{array}{l}\text { CRQ - } \\
\text { Dyspnea }\end{array}$ & $\begin{array}{r}2.8 \\
(\mathrm{IQR} 2.1-3.7)\end{array}$ & $\begin{array}{r}3.75 \\
(\mathrm{IQR} 2.8-4.6)\end{array}$ & 0.03 \\
\hline $\begin{array}{l}\text { CRQ - } \\
\text { Fatigue }\end{array}$ & $\begin{array}{r}3.25 \\
(\mathrm{IQR} 2.25-3.75)\end{array}$ & $\begin{array}{r}4.0 \\
(I Q R ~ 3.38-4.63)\end{array}$ & 0.67 \\
\hline $\begin{array}{l}\text { CRQ - } \\
\text { Mastery }\end{array}$ & $\begin{array}{r}4 \\
(\mathrm{IQR} 2.13-4.63) \\
\end{array}$ & $\begin{array}{r}4.5 \\
(I Q R ~ 3.38-4.88) \\
\end{array}$ & 0.058 \\
\hline $\begin{array}{l}\text { CRQ - } \\
\text { Emotion }\end{array}$ & $\begin{array}{r}4.14 \\
(\mathrm{IQR} 3.0-5.1)\end{array}$ & $\begin{array}{r}4.43 \\
(I Q R ~ 3.93-5.15)\end{array}$ & 0.3 \\
\hline $\begin{array}{l}\text { Chronic } \\
\text { Respiratory } \\
\text { Questionnaire } \\
\text { total }\end{array}$ & $\begin{array}{r}13.71 \\
(\text { IQR 9.38 - 16.68) }\end{array}$ & 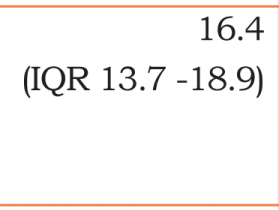 & 0.054 \\
\hline $\begin{array}{l}\text { Calgary - } \\
\text { Daily Function }\end{array}$ & $\begin{array}{r}3.64 \\
(I Q R ~ 3.41-5) \\
\end{array}$ & $\begin{array}{r}4.91 \\
(\text { IQR } 4.32-5.48) \\
\end{array}$ & 0.007 \\
\hline $\begin{array}{l}\text { Calgary - } \\
\text { Social Interact }\end{array}$ & $\begin{array}{r}5.83 \\
(\mathrm{IQR} 3.36-6.62) \\
\end{array}$ & $\begin{array}{r}6.11 \\
(I Q R ~ 4.84-6.5) \\
\end{array}$ & 0.88 \\
\hline $\begin{array}{l}\text { Calgary - } \\
\text { Emotional }\end{array}$ & $\begin{array}{r}4.91 \\
(\mathrm{IQR} 3.05-5.96)\end{array}$ & $\begin{array}{r}5.36 \\
(\mathrm{IQR} 4.41-6)\end{array}$ & 0.16 \\
\hline $\begin{array}{l}\text { Calgary - } \\
\text { Symptoms }\end{array}$ & $\begin{array}{r}3 \\
(\mathrm{IQR} 1.85-4.6)\end{array}$ & $\begin{array}{r}2.6 \\
(\mathrm{IQR} 2.4-4.9) \\
\end{array}$ & 0.81 \\
\hline $\begin{array}{l}\text { Sleep Apnea } \\
\text { Quality of } \\
\text { Life Index }\end{array}$ & $\begin{array}{r}4.34 \\
(I Q R ~ 3.44-5.6)\end{array}$ & $\begin{array}{r}4.78 \\
(\mathrm{IQR} 4.64-5.6)\end{array}$ & 0.38 \\
\hline $\begin{array}{l}\text { Severe } \\
\text { Respiratory } \\
\text { Insufficiency } \\
\text { Questionnaire } \\
\text { Summary Total } \\
\end{array}$ & 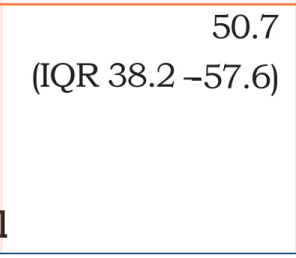 & $\begin{array}{r}58.6 \\
(I Q R ~ 46.0-60.4)\end{array}$ & 0.05 \\
\hline
\end{tabular}

Data are presented as mean \pm standard deviation or median and interquartile range.

CRQ: Chronic Respiratory Questionnaire; Calgary: Calgary Sleep Apnea Quality of Life index.

trial recruited patients after acute ventilatory failure episodes. They were unable to demonstrate a difference in time to readmission or mortality with the addition of NPPV. The majority of the control group in this study at 3 months had a $\mathrm{PaCO}_{2}<51 \mathrm{mmHg}$ and hence would not have qualified for the Kohnlein study. This may have provided a control group that would naturally improve without HI-NPPV support leading to a negative result.
Our study was not designed to assess survival.

We noted an improvement in health-related quality of life using the SRI questionnaire and the Calgary SAQLI, 2 disease-specific measures of quality of life. The mechanism by which this is achieved is unclear but may reflect a reduction in residual volume. The small change in residual volume did not meet statistical significance but this may reflect population size. We were unable to demonstrate any improvement in lung function parameters or maximal inspiratory muscle pressures in contrast to the findings of Windisch et al. ${ }^{14,15}$ Additionally, repeat polysomnography at 3 months did not show any difference in sleep efficiency or quality. These polysomnographs were not performed with ventilator assistance, as such cannot be used as evidence that HI-NPPV has no detrimental effect on sleep architecture. Patient comfort with high pressures is often cited as reason not to adequately titrate NIV in COPD. Our patients tolerated the treatment well and 7 of the patients chose to continue the treatment after the study. COPD patients have been shown to tolerate chronic NPPV poorly in comparison to neuromuscular disease patients. ${ }^{26}$ Acclimatization to NIV in COPD may be slow and patients often increasingly use NIV as their disease progresses to ameliorate daytime symptoms. The mechanism by which $\mathrm{PaCO}_{2}$ is reduced would appear to be through HI-NPPV mediated augmentation of nocturnal ventilation. The beneficial effects of which are thought to include improved respiratory system efficiency, resting of chronically fatigued respiratory muscles and improved respiratory system compliance by reducing nocturnal atelectasis. ${ }^{11}$ Resetting of chemoreceptor sensitivity for hypercapnia has been shown to increase ventilatory responsiveness to hypercapnia after NIPPV. ${ }^{27}$

Adherence with HI-NPPV in our study was in line with previous studies. ${ }^{6,18}$ Two patients dropped out early due to poor tolerance with HI-NPPV, and of the 9 remaining participants, 5 (56\%) were adherent with HI-NPPV. This is despite advances in ventilator design, usability and hospitalizing the patients for up to 3 nights to titrate and familiarize the patient with $\mathrm{HI}$ NPPV. This calls into question the utility of HI-NPPV outside of the research setting.

The weaknesses of our study are its small sample size and lack of objective adherence data. The study was initially designed as a multicenter study but due to poor recruitment response at other clinical centers patients were enrolled only from Temple University Hospital. 
It was not felt to reflect protocol design or HI-NPPV. However, it was designed as a pilot study to assess feasibility and safety of HI-NPPV in our patient group and as result did not require a large sample size.

The strengths of the study were the inpatient titration of HI-NPPV to maximize tolerance and efficacy combined with the extensive characterization of the patient group. This is also the first time HI-NPPV has been studied in the United States and in a predominantly female population.

\section{Conclusion}

In our pilot study of HI-NPPV in stable severe COPD with moderately severe resting hypercapnia, use of HINPPV demonstrated a significant effect on reducing $\mathrm{PaCO}_{2}$ and improving quality of life measures. During the 3-month period of daily use, tolerance and adherence with HI-NPPV in our participants was similar to that reported in prior studies. Future studies are needed to delineate the optimal candidate for HI-NPPV, the most effective settings to provide optimal ventilation and enhance patient compliance with chronic nocturnal use.

\section{Acknowledgements}

The study was supported by Philips Respironics, USA but they were not involved in data collection, interpretation or manuscript preparation. All authors contributed to the study concept and design, the statistical analysis, interpretation, writing, and critical review of the manuscript. All authors read and approved the final manuscript. The authors thank anonymous reviewers for their comments and suggestions.

\section{Declaration of Interest}

M. Weir, N. Marchetti, A. Czysz and G. Criner have no conflicts of interest to disclose regarding the content of this article. N. Hill acts in an advisory capacity for ResMed, and Philips Respironics. F. Sciurba acts in an advisory capacity for ResMed. P. Strollo has received grants and consultant fees from Philips Respironics and ResMed. 


\section{References}

1. Burrows B. Course and prognosis of patients with chronic airways obstruction. Chest. 1980;77(2 Suppl):250-251.

doi: http://dx.doi.org/10.1378/chest.77.2_Supplement.250

2. Vitacca M, Foglio K, Scalvini S, Marangoni S, Quadri A, Ambrosino N. Time course of pulmonary function before admission into ICU. A twoyear retrospective study of COLD patients with hypercapnia. Chest. 1992;102(6):1737-1741.

doi: http://dx.doi.org/10.1378/chest.102.6.1737

3. Chu CM, Chan VL, Lin AWN, Wong IWY, Leung WS, Lai CKW. Readmission rates and life threatening events in COPD survivors treated with non-invasive ventilation for acute hypercapnic respiratory failure . Thorax. 2004. 59 (12): 10201025. doi: http://dx.doi.org/10.1136/thx.2004.024307

4. Galli JA, Krahnke JS, James Mamary A, Shenoy K, Zhao $\mathrm{H}$, Criner GJ. Home non-invasive ventilation use following acute hypercapnic respiratory failure in COPD. Respir Med. 2014;108(5):722-728.

doi: http://dx.doi.org/10.1016/j.rmed.2014.03.006.

5. Crockett AJ, Cranston JM, Moss JR, Alpers JH. A review of long-term oxygen therapy for chronic obstructive pulmonary disease. Respir Med. 2001; 95(6):437 -443.

doi: http://dx.doi.org/10.1053/rmed.2001.1064

6. Struik FM, Lacasse Y, Goldstein R, Kerstjens HM, Wijkstra PJ. Nocturnal non-invasive positive pressure ventilation for stable chronic obstructive pulmonary disease. Cochrane Database Syst Rev. 2013;6

doi: http://dx.doi.org/10.1002/14651858.cd002878.pub2

7. Laghi F, Tobin MJ. Disorders of the respiratory muscles. Am J Resp Crit Care Med. 2003; 168: 10-43.

doi: http://dx.doi.org/10.1164/rccm.2206020

8. Braun NMT, Marino WD. Effect of daily intermittent rest of respiratory muscles in patients with severe chronic airflow limitation (cal). Chest. 1984; 85(6_Sup):59S-60S.

9. Struik FM, Sprooten RT, Kerstjens HA, et al. Nocturnal non-invasive ventilation in COPD patients with prolonged hypercapnia after ventilatory support for acute respiratory failure: A randomised, controlled, parallel-group study. Thorax. 2014;69(9):826-834.

doi: http://dx.doi.org/10.1136/thoraxjnl-2014-205126

10. Roussos C. Function and fatigue of respiratory muscles. Chest. 1985;88(2_Sup):124S-132S.

11. Mehta S, Hill NS. Noninvasive ventilation. Am J Respir Crit Care Med. 2001;163(2):540-577.

doi: http://dx.doi.org/10.1164/ajrccm.163.2.9906116

12. Elliott M. Domiciliary NIV for COPD: Where are we now? Lancet Respir Med. 2014;2(9):672-673. doi: http://dx.doi.org/10.1016/S2213-2600(14)70159-6

13. Windisch W, Kostic S, Dreher M, Virchow JC, Jr, Sorichter S. Outcome of patients with stable COPD receiving controlled noninvasive positive pressure ventilation aimed at a maximal reduction of $\mathrm{pa}\left(\mathrm{CO}_{2}\right)$. Chest. 2005;128(2):657-662. doi: http://dx.doi.org/10.1378/chest.128.2.657

14. Windisch W, Dreher M, Storre JH, Sorichter S. Nocturnal noninvasive positive pressure ventilation: Physiological effects on spontaneous breathing. Respir Physiol Neurobiol. 2006;150(23):251. doi: http://dx.doi.org/10.1016/j.resp.2005.05.017
15. Windisch W, Haenel M, Storre JH, Dreher M. High-intensity non-invasive positive pressure ventilation for stable hypercapnic COPD. Int J Med Sci. 2009;6(2):72-76. doi: http://dx.doi.org/10.7150/ijms.6.72

16. Windisch W, Vogel M, Sorichter S, et al. Normocapnia during nIPPV in chronic hypercapnic COPD reduces subsequent spontaneous $\mathrm{PaCO}_{2}$. Respir Med. 2002; 96(8):572-579. doi: http://dx.doi.org/10.1053/rmed.2002.1326

17. Windisch W. Quality of life in home mechanical ventilation study group. Impact of home mechanical ventilation on healthrelated quality of life. Eur Respir J. 2008; 32(5):1328-1336. doi: http://dx.doi.org/10.1183/09031936.00066407

18. Kohnlein T, Windisch W, Kohler D, et al. Non-invasive positive pressure ventilation for the treatment of severe stable chronic obstructive pulmonary disease: A prospective, multicentre, randomised, controlled clinical trial. Lancet Respir Med. 2014; 2(9): 678-705.

doi: http://dx.doi.org/10.1016/S2213-2600(14)70153-5

19. The global initiative for chronic obstructive lung disease (GOLD). GOLD website. http://www.goldcopd.com/guidelinesglobal- -for-diagnosis-management.html. Published January 2015. Accessed March 12, 2015.

20. Guyatt GH, Berman LB, Townsend M, Pugsley SO, Chambers LW. A measure of quality of life for clinical trials in chronic lung disease. Thorax. 1987; 42(10):773-778. doi: http://dx.doi.org/10.1136/thx.42.10.773

21. Flemons WW, Reimer MA. Development of a disease-specific health-related quality of life questionnaire for sleep apnea. Am J Respir Crit Care Med. 1998; 158(2):494-503. doi: http://dx.doi.org/10.1164/ajrccm.158.2.9712036

22. Windisch W, Freidel K, Schucher B, et al. The severe respiratory insufficiency (SRI) questionnaire: A specific measure of healthrelated quality of life in patients receiving home mechanical ventilation. J Clin Epidemiol. 2003; 56(8):752-759. doi: http://dx.doi.org/10.1016/S0895-4356(03)00088-X

23. Meecham Jones DJ, Paul EA, Jones PW, Wedzicha JA. Nasal pressure support ventilation plus oxygen compared with oxygen therapy alone in hypercapnic COPD. Am J Respir Crit Care Med. 1995;152(2):538-544.

doi: http://dx.doi.org/10.1164/ajrccm.152.2.7633704

24. Dreher M, Storre JH, Schmoor C, Windisch W. High-intensity versus low-intensity non-invasive ventilation in patients with stable hypercapnic COPD: A randomised crossover trial. Thorax. 2010;65(4):303-308

doi: http://dx.doi.org/10.1136/thx.2009.124263

25. Meyer TJ. Noninvasive positive pressure ventilation to treat respiratory failure. Ann Intern Med. 1994; 120(9):760. doi:http://dx.doi.org/10.7326/0003-4819-120-9-19940501000008

26. Criner GJ, Brennan K, Travaline JM, Kreimer D. Efficacy and compliance with noninvasive positive pressure ventilation in patients with chronic respiratory failure. Chest. 1999;116(3):667675. doi: http://dx.doi.org/10.1378/chest.116.3.667

27. Elliott MW, Mulvey DA, Moxham J, Green M, Branthwaite MA. Domiciliary nocturnal nasal intermittent positive pressure ventilation in COPD: Mechanisms underlying changes in arterial blood gas tensions. Eur Respir J. 1991;4(9):1044-1052. 